Jurnal Keperawatan Silampari

Volume 4, Nomor 2, Juni 2021

e-ISSN: 2581-1975

p-ISSN: 2597-7482

DOI: https://doi.org/10.31539/jks.v4i2.1938

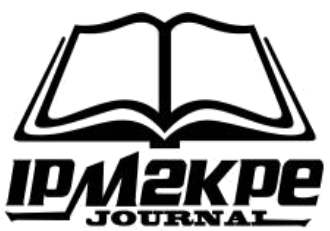

\title{
TERAPI MUSIK EFEKTIF TERHADAP PENURUNAN KECEMASAN PADA PASIEN KANKER
}

\author{
Nurlina ${ }^{1}$, Yuliana Syam ${ }^{2}$, Ariyanti Saleh ${ }^{3}$ \\ Rumah Sakit Umum Lasinrang Pinrang ${ }^{1}$ \\ Universitas Hasanuddin ${ }^{2,3}$ \\ Irwanlina8@gmail.com ${ }^{1}$
}

\begin{abstract}
ABSTRAK
Penelitian ini bertujuan untuk mengetahui efektivitas terapi musik terhadap penurunan kecemasan pasien kanker. Metode penelitian ini adalah tinjauan literatur menggunakan lima database yaitu PubMed, ProQuest, Science Direct, Clinicalkey dan Google Scholar dengan menggunakan kata kunci berdasarkan PICO. Hasil penelitian menunjukkan bahwa lima artikel yang dianalisis, semua artikel melaporkan bahwa terapi musik efektif terhadap penurunan kecemasan pasien kanker. Musik memiliki efek, psikologis, fisik, sosial dan spiritual yang dapat meningkatkan dukungan pada perawatan pasien kanker, mampu meningkatkan mood dan meningkatkan kualitas hidup pasien kanker, sehingga dapat diaplikasikan dalam pemberian intervensi keperawatan untuk menurunkan kecemasannya. Simpulan, terapi musik merupakan salah satu terapi yang efektif untuk menurunkan kecemasan mulai dari anak-anak, dewasa sampai usia lanjut.
\end{abstract}

Kata Kunci: Kanker, Kecemasan, Terapi Musik

\section{ABSTRACT}

This study aims to determine the effectiveness of music therapy in reducing anxiety in cancer patients. The research method is a literature review using five databases, namely PubMed, ProQuest, Science Direct, Clinicalkey, and Google Scholar, using keywords based on PICO. The results showed that the five articles analyzed all articles reported that music therapy effectively reduced anxiety in cancer patients. Music has psychological, physical, social, and spiritual effects that can increase support for cancer patient care, improve mood, and improve the quality of life of cancer patients to provide nursing interventions to reduce anxiety. In conclusion, music therapy is an effective therapy to reduce anxiety from children, adults to the elderly.

Keywords: Cancer, Anxiety, Music Therapy

\section{PENDAHULUAN}

Kecemasan pada pasien kanker merupakan gangguan psikologi yang disebabkan karena pasien menghadapi ketidakpastian, kekhawatiran tentang efek pengobatan kanker, takut akan perkembangan kanker yang mengakibatkan kematian, dalam beberapa situasi mereka merasa marah, takut sedih dan tertekan serta seringkali mengalami perubahan 
suasana hati (Baqutayan, 2019). Kecemasan sangat umum terjadi dan tidak butuh spesialis untuk penanganan, namun bila kondisinya kronis, ditandai dengan kurangnya minat, suasana hati terkadang tidak menentu, hilangnya kesenangan secara terus menerus, sehingga perlu upaya penanganan agar bisa berfungsi secara normal (Roddis \& Tanner, 2020).

Hasil identifikasi 80 pasien kanker, dimana gejala kecemasan yang muncul seperti kelelahan, marah secara emosional, kurang tidur, kesal, agresif, merasa putus asa, sulit menerima penyakit, merasa membebani keluarga karena tidak bisa sembuh sepenuhnya, serta memikirkan pertumbuhan kanker yang menyebar keseluruh tubuh dalam waktu yang cepat (Baqutayan, 2019). Dengan demikian, dibutuhkan tindakan untuk mengatasi dampak buruk yang akan terjadi.

Beberapa penelitian sebelumnya menyebutkan bahwa terapi musik efektif untuk penurunan kecemasan pasien kanker. Penelitian yang dilakukan oleh Kühlmann et al., (2016) membuktikan bahwa terapi musik memberikan manfaat dan efek jangka pendek kepada orang yang mengalami depresi selain itu terapi musik mampu menunjukkan khasiat penurunan tingkat kecemasan, sehingga diharapkan peneliti mempertimbangkan penggunaan intervensi terapi musik untuk penurunan tingkat kecemasan dan depresi pasien kanker.

Terapi musik merupakan intervensi keperawatan, dimana musik dijadikan sebagai media untuk aktifitas terapeutik dengan tujuan untuk memelihara, memperbaiki serta pengembangan kesehatan mental, kesehatan fisik, dan kesehatan emosi (Padila et al., 2020). Adapun praktik keperawatan berbasis bukti yang berkembang menunjukkan kemajuan dalam membantu pasien menurunkan kecemasan yaitu terapi musik (Li et al., 2020).

Terapi musik mampu meningkatkan mutu dan kualitas hidup pasien kanker yang dirawat di rumah, dimana akan berdampak pada situasi fisik serta psikologi pasien yang dirawat. Dengan intervensi ini, penurunan komsumsi obat untuk masalah kecemasan, rasa sakit serta susah tidur, mampu meningkatkan suasana hati, mengurangi ketegangan sehingga meningkatkan mutu kehidupan dan kepuasan pasien (Valero-Cantero et al., 2020).

Musik memiliki efek psikologis, fisik, sosial, dan spiritual yang dapat meningkatkan dukungan perawatan serta mampu meningkatkan mood dan meningkatkan kualits hidup pasien kanker (Nuwa \& Kiik, 2020). Meskipun dampak positif dari terapi musik ini masih diperdebatkan, namun hasil penelitian yang dilakukan oleh Li et al., 2020 membuktikan bahwa terapi musik efektif menurunkan kecemasan pasien kanker, di mana terapi musik dan seni merupakan metode yang digunakan untuk mengelola keadaan psikologi pasien.

Penelitain lain menyebutkan bahwa intervensi terapi musik secara signifikan mengurangi komplikasi fisiologis dan psikologi dari pasien yang menderita osteosarcoma, efektif dalam pengurangan rasa sakit, gelisah dan mampu meningkatkan kualitas tidur pasien (Liu et al., 2019). Dalam tinjauan ini akan dibahas terkait intervensi terapi musik pada pasien kanker yang akan menjalani tindakan medis seperti kemoterapi, brakiterapi dan pre operasi.

\section{METODE PENELITIAN}

Metode penelitian ini merupakan tinjauan literature. Penelusuran hasil publikasi ilmiah dengan rentang tahun 2017 - 2020 dengan menggunakan beberapa database untuk pecarian artikel seperti PubMed, ProQuest, Science Direct, Clinicalkey dan Google Scholar 
dengan metode PICO/patient, intervention, comparison and outcame. Setiap database dilakukan pencarian dengan menggunakan kata kunci yaitu ; P: Cancer OR Carsinoma, I: Musik therapy, C: -, O: Anxietas.

Berdasarkan hasil screening ditemukan lima artikel yang memenuhi kriteria inklusi dan relevan dengan pertanyaan penelitian. Kriteria inklusi dalam tinjauan literature ini antara lain: (1) Responden adalah pasien dengan kanker (2) Intervensi yang digunakan adalah terapi musik, (3) Hasil penelitian menunjukkan efektivitas terapi musik terhadap kecemasan. Sedangkan kriteria eksklusi antara lain: (1) Artikel yang tidak sesuai dengan pertanyaan penelitian, (2) artikel duplikat, (3) Tidak full text, (4) Bukan bahasa inggris, (5) Artikel tidak terbuka, (6) Artikel tidak sesuai dengan hasil penelitian.

Desain penelitian dalam tinjauan literature ini adalah Eksperimen, Prospective RCT single blinded, RCT double blinded, Cross Sectional yang melibatkan responden pria dan wanita dengan batasan umur dari 18 tahun hingga 65 tahun dari berbagai tempat.

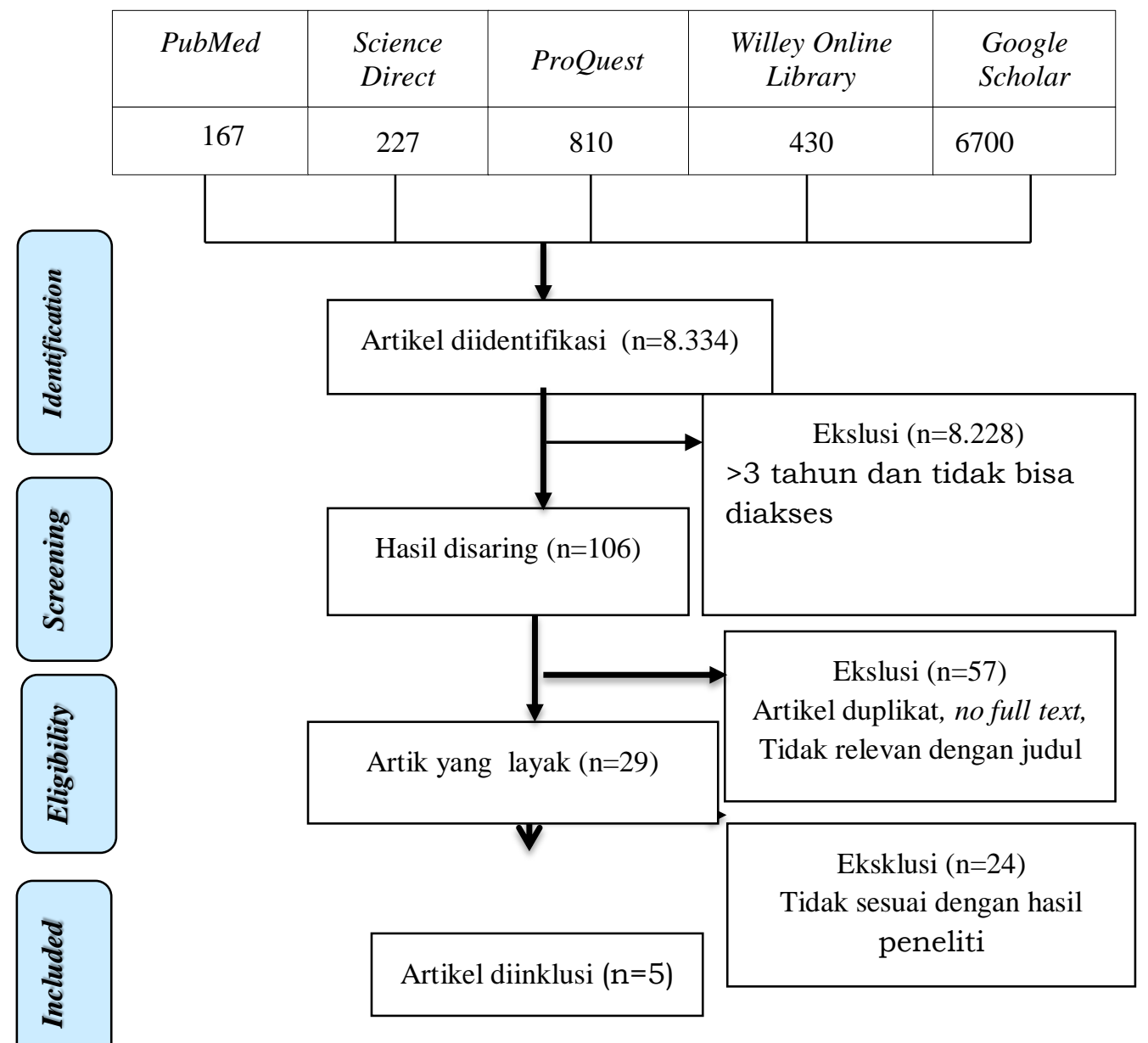

Gambar. 1

Flow Diagram Pemilihan Studi 


\section{HASIL PENELITIAN}

Tabel. 1

Deskripsi Studi dan Hasil Studi

\begin{tabular}{|c|c|c|c|c|}
\hline No & $\begin{array}{l}\text { Pengarang, Judul, } \\
\text { Jenis Literatur }\end{array}$ & Tahun & $\begin{array}{c}\text { Tujuan } \\
\text { Penelitian }\end{array}$ & Hasil Temuan \\
\hline 1. & $\begin{array}{l}\text { Yangfan et al., } \\
\text { Effect of } \\
\text { aromatherapy and } \\
\text { musik intervention } \\
\text { on pain and anxious } \\
\text { for breast cancer } \\
\text { patiens in the } \\
\text { perioperative } \\
\text { period, } \\
\text { A Randomized } \\
\text { Study }\end{array}$ & 2018 & $\begin{array}{l}\text { Tujuan } \\
\text { penelitian: } \\
\text { Untuk meneliti } \\
\text { efek dari aroma } \\
\text { terapi dan } \\
\text { intervensi musik } \\
\text { terhadap } \\
\text { kecemasan dan } \\
\text { rasa sakit } \\
\text { dipayudara } \\
\text { pasien periode } \\
\text { pre operasi }\end{array}$ & $\begin{array}{l}\text { Hasil menunjukkan secara } \\
\text { signifikan skala rasa sakit } \\
\text { meningkat pada pasca } \\
\text { operasi(T2,T3) dibanding } \\
\text { dengan operasi } \\
\text { sebelumnya(T1). Kelompok } \\
\text { terapi ini menunjukkan } \\
\text { penurunan rasa sakit setelah } \\
\text { operasi (T3) disbanding } \\
\text { dengan kelompok control } \\
\text { (P<0,05). Skala kecemasan } \\
\text { tertinggi pada masa pra } \\
\text { pembedahan (T1). Selama } \\
\text { pemulihan, anastesi, } \\
\text { kecemasan pasien dipasca } \\
\text { operasiT2 dan T3 } \\
\text { dikelompok- kelompok } \\
\text { terapi secara signifikan } \\
\text { berkurang disbanding } \\
\text { kelompok kontrol }\end{array}$ \\
\hline 2. & $\begin{array}{l}\text { Nuwa \& Kiik, } \\
\text { Pengaruh Spiritual } \\
\text { Guided Imagery } \\
\text { and Musik terhadap } \\
\text { kecemasan pasien } \\
\text { kanker yang } \\
\text { menjalani } \\
\text { kemoterapi, } \\
\text { Quasi experimental } \\
\text { dengan rancangan } \\
\text { one group pre and } \\
\text { post test with } \\
\text { control group } \\
\text { design. }\end{array}$ & 2020 & $\begin{array}{l}\text { Tujuan } \\
\text { penelitian: } \\
\text { Untuk } \\
\text { mengetahui } \\
\text { pengaruh } \\
\text { Spiritual Guided } \\
\text { Imagery and } \\
\text { Musik terhadap } \\
\text { kecemasan } \\
\text { pasien kanker } \\
\text { yang menjalani } \\
\text { kemoterapi. }\end{array}$ & $\begin{array}{l}\text { Hasil menunjukkan } \\
\text { sebanyak } 73,3 \% \text { dan } 26,7 \\
\text { pasien memiliki kecemasan } \\
\text { berat dan sedang saat pre } \\
\text { test, menjadi kecemasan } \\
\text { sedang } 56,7 \% \text { dan } \\
\text { kecemasan ringan } 43,3 \% \\
\text { pada pengukuran } 30 \text { menit } \\
\text { sebelum kemoterapi dan } \\
\text { pada akhir pengukuran } \\
\text { berada pada kecemasan } \\
\text { ringan } 63,4 \% \text { dan tidak ada } \\
\text { kecemasan } 33,3 \% \text { dan } \\
\text { sisanya } 3,3 \% \text { masih } \\
\text { mengalami kecemasan. } \\
\text { Analisis uji GLM repeated } \\
\text { measure post hock banferoni } \\
\text { diketahui } p \text { value=0,001, } \\
\text { dengan nilai } r \text { square }=0,29\end{array}$ \\
\hline 3. & $\begin{array}{l}\text { Aulia et al., } \\
\text { Effectivenes of } \\
\text { therapy in reducing } \\
\text { the level of anxiety } \\
\text { among cancer } \\
\text { patients undergoing } \\
\text { chemotherapy,Eksp }\end{array}$ & 2019 & $\begin{array}{l}\text { Tujuan } \\
\text { penelitian: } \\
\text { Untuk } \\
\text { mengevaluasi } \\
\text { efektifitas terapi } \\
\text { musik terhadap } \\
\text { tingkat }\end{array}$ & $\begin{array}{l}\text { Hasil yang didapatkan dari } \\
\text { ketiga sesi terapi musik } \\
\text { secara signifikan } \\
\text { menurunkan tingkat } \\
\text { kecemasan pasien kanker } \\
\text { yang menjalani kemoterapi } \\
(\mathrm{p}<0,001) \text { pada kelompok }\end{array}$ \\
\hline
\end{tabular}




\begin{tabular}{|c|c|c|c|c|}
\hline & $\begin{array}{l}\text { erimen semu } \\
\text { dengan tekhnik } \\
\text { nonprobability } \\
\text { sampling }\end{array}$ & & $\begin{array}{l}\text { kecemasan } \\
\text { pasien kanker } \\
\text { yang menjalani } \\
\text { kemoterapi }\end{array}$ & $\begin{array}{l}\text { intervensi, selain itu } \\
\text { didapatkan (p-0,139) dengan } \\
\text { demikian tidak ada } \\
\text { penurunan yang signifikan } \\
\text { pada kelompok control. }\end{array}$ \\
\hline 4. & $\begin{array}{l}\text { Nurhalim, } \\
\text { The effect of } \\
\text { classical musik } \\
\text { therapy on the } \\
\text { anxiety of cervical } \\
\text { cancer patients with } \\
\text { brachytherapy in } \\
\text { the radiation } \\
\text { oncology service } \\
\text { unit of Cipto } \\
\text { Mangunkusumo } \\
\text { Jakarta, } \\
\text { Quasi } \\
\text { eksperimental tipe } \\
\text { one group pre dan } \\
\text { post test }\end{array}$ & 2020 & $\begin{array}{l}\text { Tujuan } \\
\text { penelitian: } \\
\text { Untuk } \\
\text { mengetahui } \\
\text { efektivitas terapi } \\
\text { musik klassik } \\
\text { terhadap } \\
\text { kecemasan } \\
\text { pasien kanker } \\
\text { serviks dengan } \\
\text { tindakan } \\
\text { brakiterapi }\end{array}$ & $\begin{array}{l}\text { Hasil menunjukkan bahwa } \\
\text { terapi musik klassik mampu } \\
\text { menurunkan tingkat } \\
\text { kecemasan sebesar } 11,62 \% \\
\text { dengan } p \text { value sebesar } 0,00 \\
\text { atau ( } p \text { value }<0,05)\end{array}$ \\
\hline 5. & $\begin{array}{l}\text { Celebi, } \\
\text { The effect of musik } \\
\text { therapy during } \\
\text { colonoscopy on pain, } \\
\text { anxiety and patient } \\
\text { confort: A randomized } \\
\text { controlled trial, Study } \\
\text { double blind RCT }\end{array}$ & 2020 & $\begin{array}{l}\text { Tujuan } \\
\text { penelitian: } \\
\text { Untuk melihat } \\
\text { efektivitas terapi } \\
\text { musik terhadap } \\
\text { pengurangan } \\
\text { kecemasan dan } \\
\text { depresi dari } \\
\text { pasien kanker } \\
\text { yang akan } \\
\text { menjalani } \\
\text { tindakan } \\
\text { kemoterapi }\end{array}$ & $\begin{array}{l}\text { Hasil penelitian } \\
\text { menunjukkan bahwa } \\
\text { intervensi terapi musik } \\
\text { menunjukkan dampak } \\
\text { terhadap penurunan } \\
\text { kecemasan }(\mathrm{p}<5) \text {. Efektifitas } \\
\text { penurunan kecemasan pada } \\
\text { pasien kanker terlihat lebih } \\
\text { baik pada minggu ke } 6 \text {. }\end{array}$ \\
\hline
\end{tabular}

Berdasarkan tabel 1 menunjukkan bahwa dari lima artikel penelitian yang dilakukan tinjauan literatur, semua penelitian melaporkan bahwa terapi musik efektif terhadap penurunan kecemasan pasien kanker yang menjalani tindakan medis, diantaranya penelitian menunjukkan ada pengaruh SGIM terhadap penurunan kecemasan pasien kanker yang menjalani kemoterapi. Penurunan tingkat kecemasan pada pasien kanker serviks yang menjalani tindakan brakiterapi. Terapi musik secara signifikan menurunkan tingkat kecemasan pasien kanker yang menjalani kemoterapi; Aromaterapi dan terapi musik dapat mengurangi kecemasan yang responsif serta rasa sakit pada penderita kanker payudara; Iintervensi terapi musik menunjukkan dampak terhadap penurunan kecemasan $(\mathrm{p}<5)$. Efektifitas penurunan kecemasan pada pasien kanker terlihat lebih baik pada minggu ke 6 .

Berdasarkan hasil pencarian literature ditemukan lima artikel yang relevan dan memenuhi kriteria inklusi. Penilitian-penilitian tersebut umumnya menilai efektifitas terapi musik terhadap kecemasan pasien kanker dengan menggunakan instrumen penilaian kecemasan dengan skala STAI, DASS dan Visual Analog Scale (VAS), dan HARS. Dalam 
sebuah literature menjelaskan bahwa terapi musik mampu menstabilkan denyut jantung, laju pernafasan dan juga menstabilkan tekanan darah penderita.

\section{PEMBAHASAN}

Berdasarkan hasil pencarian literature ditemukan lima artikel yang relevan dan memenuhi kriteria inklusi. Penilitian-penilitian tersebut umumnya menilai efektifitas terapi musik terhadap kecemasan pasien kanker dengan menggunakan instrument penilaian kecemasan dengan skala STAI, DASS dan Visual Analog Scale (VAS) dan HARS. Dalam sebuah literatur menjelaskan bahwa terapi musik mampu menstabilkan denyut jantung, laju pernafasan dan juga menstabilkan tekanan darah penderita (Nuwa \& Kiik, 2020).

Penelitian yang dilakukan oleh Nuwa \& Kiik (2020) menunjukkan sebanyak 73,3\% dan 26,7 pasien memiliki kecemasan berat dan sedang saat pre test, menjadi kecemasan sedang $(56,7 \%)$ dan kecemasan ringan $(43,3 \%)$ pada pengukuran 30 menit sebelum kemoterapi dan pada akhir pengukuran berada pada kecemasan ringan $(63,4 \%)$ dan tidak ada kecemasan (33,3\%)dan sisanya 3,3\% masih mengalami kecemasan. Analisis uji GLM repeated measure post hock banferoni diketahui $p$-value $=0,001$, dengan nilai $r$ square=0,29. Hal ini menunjukkan ada pengaruh SGIM terhadap penurunan kecemasan pasien kanker yang menjalani kemoterapi. Dengan kesimpulan SGIM dapat diaplikasikan sebagai salah satu terapi komplementer dalam pemberian intervensi keperawatan di Rumah sakit untuk menurunkan kecemasan penderita kanker terutama saat pertama kali menjalani kemoterapi serta berada pada kondisi cemas.

Latif et al., (2020) memaparkan bahwa dari ketiga sesi terapi musik secara signifikan menurunkan tingkat kecemasan pasien kanker yang menjalani kemoterapi $(\mathrm{p}<0,001)$ pada kelompok intervensi, selain itu didapatkan $(\mathrm{p}-0,139)$ dengan demikian tidak ada penurunan kecemasan yang signifikan pada kelompok control. Sehingga kesimpulan dari penelitian ini bahwa terapi musik efektif dalam menurunkan tingkat kecemasan pada pasien kanker yang menjalani kemoterapi.

Penelitian yang dilakukan oleh Nurhalimah (2020) menunjukkan penurunan tingkat kecemasan pada pasien kanker serviks yang menjalani tindakan brakiterapi, dimana terapi musik klassik mampu menurunkan tingkat kecemasan sebesar 11,62\%.dengan p-value sebesar 0,00 atau ( $\mathrm{p}$ value $<0,05$ ), dengan demikian dapat disimpulkan bahwa terdapat perbedaan tinkat kecemasan sebelum dan sesudah pemberian terapi musik klassik.

Penelitian yang dilakukan oleh Yangfan et al., (2018) terhadap 100 penderita kenker payudara di ruang perawatan bedah di berbagai Rumah Sakit di provinsi Hunan. Terbagi atas kelompok intervensi yakni group aromaterapi dan group musik, serta gabungan (n25 per group). Para penderita kelompok kontrol, setelah pembedahan menerima perawatan rutin, dan dari kelompok lain menerima intervensi musik, aromaterapi atau keduanya selain perawatan biasa. Pengukuran dilakukan pada tiga titik waktu, yakni 30 menit sebelum pembedahan(T1), 30 menit setelah anestesi(T2) dan pemulihan, 4jam setelah pengangkatan tabung anestesi. Hasil menunjukkan bahwa $(\mathrm{p}<0,05)$ yaitu skala kecemasan teringgi pada pre operasi, selama pemulihan anestesi kekhawatiran penderita pasca operasi pada kelompok terapi secara signifikan berkurang dibandingkan kelompok $\operatorname{kontrol}(\mathrm{p}<0,05)$. Dengan demikian aromaterapi dan terapi musik dapat mengurangi kecemasan yang responsif serta rasa sakit pada penderita kanker payudara pada masa haid. 
Hasil peneliatian ini membuktikan bahwa intervensi terapi musik efektif mengurangi rasa sakit dan kecemasan pada pasien pasien kanker yang menjalani tindakan khemoterapi. Penelitian ini menggunakan study doule blind, RCT, dimana bertujuan untuk melihat efektifitas terapi musik terhadap pengurangan kecemasan dan depresi dari pasien kanker payudara yang akan menjalani tindakan khemoterapi. Terapi ini diberikan selama 24 minggu, setiap sesi terdiri dari 30 menit. Penelitian ini terdiri dari 60 pasien yang direkrut secara acak, yang terdiri dari 30 pasien dimasukkan dalam kelompok intervensi sedangkan 30 lainnya dimasukkan dalam kelompok control. Hasil penelitian menunjukkan bahwa intervensi terapi musik menunjukkan dampak terhadap penurunan kecemasan $(\mathrm{p}<5)$. Efektifitas penurunan kecemasan pada pasien kanker terlihat lebih baik pada minggu ke 6 . Sehingga terapi musik ini dapat direkomendasikan sebagai intervensi untuk menurunkan kecemasan pasien kanker yang akan menjalani tindakan kemoterapi (Çelebi et al., 2020)

Kecemasan pada pasien kanker merupakan gangguan psikologi yang disebabkan karena pasien menghadapi ketidakpastian, kekhawatiran tentang efek pengobatan kanker, takut akan perkembangan kanker yang mengakibatkan kematian, dalam beberapa situasi mereka merasa marah, takut sedih dan tertekan serta seringkali mengalami perubahan suasana hati (Baqutayan, 2019). Pasien kanker dengan kondisi kecemasan kronis yang ditandai dengan kurangnya minat, suasana hati terkadang tidak menentu, disertai hilangnya kesenangan secara terus menerus perlu upaya penanganan agar bisa berfungsi secara normal (Roddis \& Tanner, 2020).

Beberapa hasil penelitian membuktikan bahwa terapi musik efektif terhadap penurunan kecemasan pasien kanker, hal ini dibuktikan dari penelitian Rossetti et al., (2017) guide imagery and musik memiliki efek, psikologis, fisik, sosial dan spiritual yang dapat meningkatkan dukungan pada perawatan pasien kanker. terapi musik mampu meningkatkan mood dan meningkatkan kualitas hidup pasien kanker. Sebuah literature menjelaskan bahwa terapi musik mampu menstabilkan denyut jantung, laju pernafasan dan juga menstabilkan tekanan darah penderita (Nuwa \& Kiik, 2020; Wang et al., 2018). Terapi musik sebagai salah satu terapi komplementer yang dapat diaplikasikan dalam pemberian intervensi keperawatan di Rumah sakit untuk menurunkan kecemasan penderita kanker.

\section{SIMPULAN}

Banyak jenis terapi komlementer yang digunakan dalam penurunan kecemasan, terapi musik merupakan salah satu intervensi yang direkomendasikan, dimana intervensi ini tidak beresiko, hemat biaya, sehingga aman digunakan serta efektif untuk menurunkan kecemasan pada pasien kanker. Disamping itu selain efektif untuk menurunkan kecemasan pasien kanker, terapi musik juga dapat digunakan untuk pemulihan psikologi pasien dengan gangguan jiwa.

\section{SARAN}

Musik sangat disenangi oleh masyarakat dari berbagai usia, mulai dari anak-anak hingga dewasa bahkan sampai usia lanjut. Namun terapi musik ini sebaiknya diaplikasikan pada pasien kanker dengan rentang usia 18 - 65 tahun. Hasil tinjauan literatur ini diharapkan dapat menjadi bahan bacaan untuk tambahan pengetahuan dan informasi bagi tenaga perawat dalam menjalankan praktik keperawatan berbasis bukti di fasilitas 
kesehatan. Untuk peneliti selanjutnya diharapkan menggunakan terapi komlementer yang lain dalam penurunan tingkat kecemasan pada pasien kanker.

\section{DAFTAR PUSTAKA}

Baqutayan, S. M. (2019). How Can Anxiety Be Better Managed? Depression, Anxiety, and Coping Mechanisms among Cancer Patients. World Cancer Research Journal, 6, e1350. https://doi.org/10.32113/wcrj_20197_1350

Çelebi, D., Yılmaz, E., Sahin, S. T \& Baydur, H. (2020). The Effect of Music Therapy During Colonoscopy on Pain, Anxiety and Patient Comfort: A Randomized Controlled Trial. Complementary Therapies in Clinical Practice. 38, 101084. https://doi.org/10.1016/j.ctcp.2019.101084

Kühlmann, A. Y. R., Etnel, J. R. G., Roos-Hesselink, J. W., Jeekel, J., Bogers, A. J. J. C., \& Takkenberg, J. J. M. (2016). Systematic Review and Meta-Analysis of Music Interventions in Hypertension Treatment: A Quest for Answers. BMC Cardiovascular Disorders, 16(1), 1-9. https://doi.org/10.1186/s12872-016-0244-0

Latif, A. I., Alhidayat, N. S., Putra, S. H., Erika, K. A., Ningrat, S., \& Syahrul, S. (2020). Effectiveness of Music Therapy in Reducing the Level of Anxiety among Cancer Patients Undergoing Chemotherapy. Enfermeria Clinica, 30, 304-307. https://doi.org/10.1016/j.enfcli.2019.10.022

Li, X., Du, G., Liu, W., \& Wang, F. (2020). Music Intervention Improves the Physical and Mental Status for Patients with Breast Cancer. Medicine, 99(49), e23461. https://doi.org/10.1097/md.0000000000023461

Liu, H., Gao, X., \& Hou, Y. (2019). Effects of Mindfulness-Based Stress Reduction Combined with Music Therapy on Pain, Anxiety, and Sleep Quality in Patients with Osteosarcoma. Brazilian Journal of Psychiatry, 41(6), 540-545. https://doi.org/10.1590/1516-4446-2018-0346

Nurhalimah, P. W. P. F. (2020). The Effect of Classical Music Therapy on The Anxiety of Cervical Cancer Patients With Brachytherapy In The Radiation Oncology Service Unit of Cipto Mangunkusumo Jakarta Hospital. Jurnal Kesehatan Pasak Bumi Kalimantan, $\quad(J K P B K), \quad 3(2), \quad 10-14 . \quad$ http://ejournals.unmul.ac.id/index.php/JKPBK/article/view/4721

Nuwa, M. S., \& Kiik, S. M. (2020). Pengaruh Spiritual Guided Imagery and Music terhadap Kecemasan Pasien Kanker yang Menjalani Kemoterapi. Jurnal Ners Dan Kebidanan (Journal of Ners and Midwifery), 7(1), 95-106. https://doi.org/10.26699/jnk.v7i1.art.p095-106

Padila, P., Setiawati, S., Inayah, I., Mediani, H. S., \& Suryaningsih, C. (2020). Emosi dan Hubungan Antar Sebaya pada Anak Tunalaras Usia Sekolah Antara Terapi Musik Klasik (Mozart) dan Murrotal (Surah Ar-Rahman). Jurnal Keperawatan Silampari, 3(2), 725-763. https://doi.org/https://doi.org/10.31539/jks.v3i2.1276

Roddis, J. K., \& Tanner, M. (2020). Music Therapy for Depression. Research in Nursing and Health, 43(1), 134-136). https://doi.org/https://doi.org/10.1002/nur.22006

Rossetti, A., Chadha, M., Torres, B. N., Lee, J. K., Hylton, D., Loewy, J. V., \& Harrison, L. B. (2017). The Impact of Music Therapy on Anxiety in Cancer Patients Undergoing Simulation for Radiation Therapy. International Journal of Radiation Oncology Biology Physics, 99(1), 103-110. https://doi.org/10.1016/j.ijrobp.2017.05.003 
Valero-Cantero, I., Martínez-Valero, F. J., Espinar-Toledo, M., Casals, C., Barón-López, F. J., \& Vázquez-Sánchez, M. Á. (2020). Complementary Music Therapy for Cancer Patients in At-Home Palliative Care and Their Caregivers: Protocol for a Multicentre Randomised Controlled Trial. BMC Palliative Care, 19(1). https://doi.org/10.1186/s12904-020-00570-9

Wang, X., Zhang, Y., Fan, Y., Tan, X. S., \& Lei, X. (2018). Effects of Music Intervention on the Physical and Mental Status of Patients with Breast Cancer: A Systematic Review and Meta-Analysis. Breast Care, 13(3), 183-191). https://doi.org/10.1159/000487073

Yangfan, X., Lezhi, L., Yijia, X., Junmei, X., \& Yan, L. (2018). Effects of Aroma Therapy and Music Intervention on Pain and Anxious for Breast Cancer Patients in the Perioperative Period. Journal of Central South University (Medical Sciences), 43(6), 656-661. https://doi.org/10.11817/j.issn.1672-7347.2018.06.013 